Structure, agency and post-Fukushima nuclear policy: an Alliance-Context-Actantiality model of political change

Updated version forthcoming in Journal of Risk Research

Matthew Cotton

m.cotton@sheffield.ac.uk

\begin{abstract}
The Fukushima Daichii nuclear disaster has radically reshaped domestic Japanese energy policy, political economy and citizen-state relations within a very short time period. This destabilised period of post-Fukushima nuclear policy is considered in meta-theoretical terms, drawing upon the work of Colin Hay in describing a Punctuated Evolution model of stability and change. This in turn, draws upon the concepts of structure and agency, and the material and ideational. I assess and apply Jessop and Hay's Strategic Relational Approach (SRA) to resolving these issues, with reference to the Fukushima disaster throughout. The ontological weaknesses of the SRA are discussed, namely the weak conceptualisation of 'the material', leading to the construction of a new hybrid model. Hay's concept of Structure-StrategyAgency is augmented into one of Alliance-Context-Actantiality; drawing upon concepts from Actor Network Theory to better articulate the role of artefacts, physical and material processes in influencing stability and change in risk politics.
\end{abstract}

Key words: Fukushima, nuclear energy, Strategic Relational Approach, Actor Network Theory. 


\title{
Structure, agency and post-Fukushima nuclear policy: an Alliance-Context-Actantiality model of political change
}

\begin{abstract}
The Fukushima Daichii nuclear disaster has radically reshaped domestic Japanese energy policy, political economy and citizen-state relations within a very short time period. This destabilised period of post-Fukushima nuclear policy is considered in meta-theoretical terms, drawing upon the work of Colin Hay in describing a Punctuated Evolution model of stability and change. This in turn, draws upon the concepts of structure and agency, and the material and ideational. I assess and apply Jessop and Hay's Strategic Relational Approach (SRA) to resolving these issues, with reference to the Fukushima disaster throughout. The ontological weaknesses of the SRA are discussed, namely the weak conceptualisation of 'the material', leading to the construction of a new hybrid model. Hay's concept of Structure-StrategyAgency is augmented into one of Alliance-Context-Actantiality; drawing upon concepts from Actor Network Theory to better articulate the role of artefacts, physical and material processes in influencing stability and change in risk politics.
\end{abstract}

Key words: Fukushima, nuclear energy, Strategic Relational Approach, Actor Network Theory.

\section{Introduction}

Since the spring of 2011 the Fukushima Daiichi nuclear disaster has generated significant media and academic commentary upon the socio-cultural, ethical, policy and risk governance impacts of new build nuclear power in the face of global radiation risks, fossil fuel resource constraints and anthropogenic climate change (Hasegawa 2012b; Butler et al. 2011; Ikegami 2012). Like the 1986 Chernobyl reactor explosion before it, the Fukushima disaster caused significant anthropological shock across the developed world (Beck 1987). The disaster is not simply an accident or event, it has transformed the cultural awareness and visibility of nuclear power risks at time when it was beginning to gain 'reluctant acceptance' internationally in light of growing concerns over greenhouse gas emissions from fossil fuelbased energy sources (Bickerstaff et al. 2008). In the decade or so prior to the disaster there was something of an emerging nuclear renaissance, a growing interest and political acceptance for both existing and new nuclear power facilities, with the three largest nuclear power producing countries (France, USA and Japan) planning to extend licences and associated operating lives of most existing plants without significant public opposition (Joscow and Parsons 2012). However, the Fukushima disaster had profound implications for this nuclear renaissance, as the media spotlight on Japan in the wake of the radiation leak massively increased the socio-cultural visibility of nuclear risks across the globe (see Beck 1992 in particular). This prompted sustained, nationally organised public opposition movements to new nuclear build, not only in Japan, but also in Germany, Italy and Switzerland (World Nuclear Association 2012). These organised demonstrations have created a barrier to the political viability of nuclear new build as a viable transition pathway (Geels 2002; Foxon et al. 2010) to decarbonising electricity systems. What we see in Japan specifically, is that the disaster has punctuated the relatively stable period of policy evolution in the nuclear sphere. It disrupted and destabilised the progression towards new build nuclear in Japan (though notably has not reversed such a trend) and moreover has transformed 
discourses of energy policy futures and broader political economy and citizen-state relations in Japan within a very short time period (Hagmann 2012; Masako 2012; Brooks 2012; Butler et al. 2011).

\section{Analytical framework}

This paper has two aims. The first is to articulate the processes of political destabilisation and technology policy change occurring in post-Fukushima Japan. The second is to discuss an ontological framework for assessing the influence of physical process and material artefacts (such as leaking nuclear power stations) on risk politics, using the Fukushima disaster as a critical case through which to frame the theory. I principally focus upon three interrelated meta-theoretical issues in the social sciences, blending in examples from post-Fukushima Japanese nuclear policy throughout. Firstly, are the temporal dimensions of political stability and change, which as Marsh (2010) suggests draws secondly upon concepts of structure and agency, and thirdly upon concepts of the material and ideational.

First, it is important to clarify the terminology used. Stability and change is construed as political continuity and discontinuity following a 'punctuated evolution' (PE) model (Hay $2002 \mathrm{~b}$ ) - i.e. in terms of slow and stable policy development followed by rapid successive changes in the face of crisis. Structure and agency in this context relate to the processes of risk governance - the relationship between actors, institutions and social constraints that form the policy landscape. Jessop (2001, 2005a) and Hay's (1995, 2002b) model termed the Strategic-Relational Approach (SRA) is examined in relation to this problem. Thirdly, the material and ideational relates to, for example, the role of physical environmental hazards (from leaking nuclear reactors) and energy resource constraints when contrasted with the role of ideas in shaping policy through the strategic learning of contextually situated actors. By applying insights from Actor Network Theory a new approach is synthesised, tentatively entitled the Alliance-Context-Actantiality model (ACA), with reference to its application in risk politics.

\section{Stability and change}

The Fukushima disaster that followed the earthquake and tsunami in Spring 2011, exacerbated a critical period of intense humanitarian crisis. It forced civil evacuation from the disaster zone, it contaminated food sources, urban and rural environments, and disrupted regional energy production. However, the disaster also presents an epistemic crisis (ShraderFrechette 2011; Hagmann 2012; Rieu 2013) - a timeframe in which political change is rapid and disruptive, power relations between political actors shift, policies are created, amended or discarded, and the relationships between citizens and the instruments of the state are transformed. In understanding Fukushima as an instrument of political change, Hay argues that it is important to understand how such crises are narrated and by whom (Hay 2002b). In doing so I distinguish between the periods of nuclear policy making before and after the disaster, thus operating within Hay's model of punctuated evolution (PE) whereby politics can be mapped diachronically (change as a process over time), and dialectically (stability is understood as causing the conditions of change and vice versa). PE combines aspects of evolutionary and revolutionary change, and it allows for discontinuous differential change which is either 'modest' (evolutionary) or 'intense' (punctuated) (ibid.).

To illustrate punctuated evolution Hay applies Kuhn's (1962) terminology, adapted by Hall (1993), to differentiate a 'normal' period of policy making characterised by narration negotiated within the confines of an elite group. In this case the elite group is clear Hasegawa (2012a) terms it the "atomic village": a closed-loop relationship between politicians, government offices, academics, industrial leaders, and the media. Together, these 
actors operated with a given set of values and particular definitions of national energy policy priorities, risk management and communication, and investment liability. The outcome being stable continuity and policy evolution within existing parameters - in other words a sociotechnical regime characterised by stability allowing for incremental innovation and application (see for example Geels 2004). The power to capture the narrative around nuclear energy and to create this stable pattern of policy development lay in part, in the relative invisibility of the Japanese nuclear industry to public scrutiny. Prior to 2011 Japan had one of the most successful nuclear policy programmes in the world. As Aldrich (2012) suggests, this success was due to a mix of top-down directives, active political support and lucrative handouts to host sites, alongside politically weak environmental NGOs, tacit public acceptance, public deference to authorities and a passive tolerance of nuclear risks (see also Hasegawa 2010). Japanese public approval for nuclear power was steadily growing in the face of climate change and energy security threats. As a result, the government and associated industry bodies (including the Tokyo Electric Power Company - TEPCO, operator of the Fukushima plant) pursued ever more ambitious nuclear energy policies. This collective strategy culminated in the 2010 Strategic Energy Plan of Japan, which clearly emphasised the role that nuclear power would play as a sovereign technology i.e. one designed to ensure domestic energy security and carbon emission reduction (Toki 2012; Meltzer 2011).

This period of stable evolution was disrupted by what appeared to be an external and wholly physical intervention from the seismic activity and resultant nuclear reactor failure. The Fukushima disaster involved the interaction between unknown state-variables (for example the interaction of the earthquake, tsunami, the size of the sea wall defending the reactors from water intrusion, and the positioning of the back-up generators). This produced, what appeared to be an unanticipated surprise (and as Hoffmann-Riem and Wynne 2002 suggest, such surprises are often overlooked in risk analysis). Because the combination of seismic risks from earthquake and tsunami conditions triggered a technological catastrophe, it is the interaction of these two risk domains that has led to a dominant narrative espoused by Japanese authorities that the Fukushima disaster was akin to a 'Black Swan' event (Taleb 2007): i.e. high-profile and high impact but impossible to predict because it was beyond the realm of expectation (Hagmann 2012; Funabashi 2012; Shrader-Frechette 2011). Because the conditions for the reactor failure in the Fukushima case are discursively constructed as atypical, they have thus been narrated by policy actors within the atomic village as unforeseeable and thus ungovernable risk, in part as a means to shore up political support for nuclear new build in the period after the disaster occurred.

By contrast, numerous academic social scientists and political activists within Japan have challenged this narrative framing, revealing the contentious politics of uncertainty surrounding the risk governance of the Fukushima plant and other nuclear stations within Japan. Such opponents point out that the narration of the disaster as a black swan event is a distraction tactic - diverting attention from the fact that Japanese industry, regulatory and political circles had prior knowledge that the reactors were unsafe, evidenced for example by TEPCO's falsification of safety reports in 2002, and its non-compliance of Government mandated safety and information requirements (for discusison of these issues see ShraderFrechette 2011; Blowers 2011; Funabashi 2012; Hasegawa 2012b). This counter-narrative gained significant ground in Japanese politics in the wake of the disaster, and so within this period of political crisis, the atomic village did not maintain control of the framing of the nuclear energy narrative, as the risks of nuclear power became so clearly visible to political agents outside of the 'closed loop' (Marsh 2010; Hay 2002b). In the new post-disaster context, new narratives and narrators emerged, and so a conflict ensued akin to Kuhn's revolutionary period, as different groups of actors sought to establish a new political paradigm. 
What is important in Hay's (1996, 2002b) model of stability and change is that the two elements are conceived as dialectical - in this case one can conceptualise the Fukushima disaster not simply as an external and unforeseeable event, but rather as a culmination of factors emerging from the stable evolution of nuclear policy in the normal period. The punctuated period of rapid change was not simply political instability promulgated by an external crisis then, but rather the stable evolutionary pattern of nuclear policy that preceded the disaster created the conditions under which it could occur. Within the punctuated period the narrative conflict is analogous to the Kuhnian notion of a scientific revolution - a period in which a new paradigm of nuclear policy is forged through conflict between old and new paradigms. Within the normal evolutionary period, pro-nuclear industry, media and government authorities shielded nuclear safety concerns from public scrutiny, and regulators failed at an institutional level to protect the public from harm. The apparently unanticipated material intervention of the Fukushima disaster was borne not of a black swan event, a physical intervention of seismic activity to create an external disruption, but rather the nascent paradigm shift within Japanese energy policy can be understood as emerging from a dialectical, co-constitutive relationship between the evolutionary pre-Fukushima and punctuated post-Fukushima temporal horizons.

\section{Structure and agency}

To justify the claim of a dialectical relationship between the evolutionary and punctuated periods, it is necessary to think about the different actors involved and why certain narratives emerged based upon the constraints imposed upon different actors. In metatheoretical terms this is a problem of structure and agency that directly relates to the problem of stability and change. In this context, structure refers to the shared conditions of various collectivities of humans within the processes of material production and social reproduction, and hence the circumstantial and institutional constraints that limit the capacity of individuals to express free will (Fuller 1998). Agency therefore corresponds with political autonomy: the capacity of individuals to act in an unconstrained manner, having independence, influence and the capacity to transform (Sewell Jr 1992). Implicit to any question in the social sciences is a concern with the relationship between social agents' autonomy and the constraining effects of contextual and institutional forces acting upon them in any given situation. However, recent social scientific debate over structure-agency is mindful of a two sociologies problem of trying privilege either the macro-sociology of social structures (stressing social holism and/or structural determinism) or the micro-sociology of agency, specifying the creation of an orderly world by interacting individuals (stressing voluntarism) (O'Brien 1999; Gregson 2005; Reed 1997). Espousing one of these positions provides an incomplete metatheoretical understanding of the problem at hand, and so there has been a concerted to try and establish some sort of middle ground (Adler 1997; Carlsnaes 1992). However, in avoiding the two sociologies trap, another challenge emerges when trying to assert a point of balance between these two positions. It is not enough to simply decide what proportions of each perspective should be incorporated, because to do so would require a full empirical knowledge of any given social event, and an unbiased metric for measuring the extent to which an action has agential or structural causes (McAnulla 2005; Hay and Wincott 1998).

\section{The Strategic-Relational Approach}

In attempting to avoid both the two sociologies problem and the methodological and ontological limitations of defining structure-agency empirically; Jessop and Hay propose an 
ontological solution to the structure-agency problem. This solution is termed the StrategicRelational Approach (SRA) by Jessop, and described as a structure-strategy-agency approach by Hay (Jessop 2001, 2005a; Hay 1995, 2002a). The SRA is a dialectical model for describing the structure-agency relationship; informed by critical realist and neo-Gramscian modes of analysis (McGuirk 2004) and developed in reference to the limitations of Giddens' (1984, 1979) structuration theory (not discussed here, see Craib 1992; Willmott 1999; Archer 2003; Hay 1995).

The SRA construes structure and agency as strategically conditioning and transforming each other, with a particular emphasis upon understanding institutional stability and change (see Hay and Wincott 1998) with reference to the PE model. The SRA posits structure and agency as having ontological unity, i.e. a dialectical relationship linking the two but at the same time the two concepts can be separated analytically (Hay 2002b; Jessop 2001). Structure and agency relate to one another in a specific circumstance by introducing strategy as intentional conduct oriented towards the environment and action motivated by the intention to realize certain outcomes, objectives and goals. Agency then in relational terms becomes strategic action and structure becomes strategically selective context (Hay 2002b).

In the first instance, structure is the spatially and temporally situated configuration of internal relations that an agent is situated within. These configurations favour certain strategies for the transformation of such configurations over others to produce 'inscribed selectivities'. These, in turn, influence the capacity of social forces to engage in strategic context analysis and then pursue strategies that are variably adapted to these selectivities; including strategies aimed at circumventing or modifying their associated constraints (Jessop 2007). The concept of strategic selectivity is central to the SRA. Layers of structure act to socially condition agents and define the range of strategies they might deploy in an attempt to realise their intentions. Agents have specific spatio-temporal identities and structures have specific time-space envelopes (Jessop 2006). Agents have to gain control over the corresponding level of time and space in order to shape the physical and social structural selectivity in favour of their goals. However, the relative status of agents is not a level playing field. Time-space envelopes have contours, inevitably constraining or enabling certain actors, creating physically and politically defined structural constraints to action. Agents never have perfect knowledge of how these structures work, they cannot simply 'read off' a strategy based upon perfect knowledge of their situation, rather they must interpret their position and reflexively formulate actions on the basis of partial knowledge of how these structures work (Hay 2002b). In certain circumstances it is possible for agents to overcome the individual disadvantages created for them by strategically selective contexts and so they can break free of these constraints; and even if that is not possible, they undergo strategic learning and adapt future strategies on the basis of past outcomes and a calculation of their current situation in order to try and ensure future success (McAnnulla 2002; Hay 2002b, 1996).

In essence the process has three stages. Firstly, by bringing agency into structure a structured setting or context is created, and by bringing structure into agency a contextualised and structurally situated agent is created. Through a process of calculation the agent formulates a strategy within context. Secondly, the strategic actions of the situated agent have (partial) transformation effects on the context for future strategy, and simultaneously enhance strategic knowledge of the agent, which in turn informs future strategic calculations. Thirdly, by bringing the situated agent back into the structured setting and the structured setting back into the situated agent, the structure agency dualism is resolved and a new strategic agent and strategically selective context emerge (Hay 2002b). This process is iterative. Strategy becomes the mediating factor in social change, as both structures and agents are transformed through the dialectical process over time. 


\section{Fukushima and the strategic-relational approach}

To analyse the Fukushima disaster in SRA terms, it is firstly the combination of material (old reactor designs, seismic activity, inadequate sea defences etc.) and ideational components (regulatory institutional failures) that forms a structured setting for the disaster to occur. In ideational terms, the Japanese nuclear policy framework and the culture of the atomic village produces structurally inscribed selectivities that favour key situated strategic agents and their strategy formulation to reinforce the time-space envelope of pro-nuclear policy during the evolutionary period prior to the Fukushima disaster. This encouraged and reinforced the material (and hence technological) path dependency of nuclear technology research, development and deployment. Citizen actors in Fukushima prefectures (and across Japan as a whole) could be considered to lack access to the specific time-space envelope by which this policy structure was bound, in part because of the socio-cultural invisibility of nuclear risks, combined with a trusting and deferential position that citizens took in relation to the atomic village. Here the structurally inscribed selectivity could be described as a postdemocratic condition (to use the terminology of Swyngedouw 2007); citizens were either ignorant of risks, passive or acquiescent towards the atomic village, and so risk governance was shaped in private by an interaction between elected governments and powerful business interests. This configuration of actors reveals differentiated spatio-temporal identities, stratified across Japanese society. These identities reflexively reinforced what Jessop terms 'the institutional matrix': in this case of the atomic village, of sovereign nuclear technologies and tacit public support for new-build nuclear. The evolutionary period of change prior to Fukushima thus had relative structural stability or coherence and so produced what Jessop (2006) terms a spatio-temporal fix.

The earthquake and tsunami generated a physical intervention into this spatiotemporal fix, and the ideational consequences of this material change are clear. Contaminated and displaced citizens became subject both to material hazards and political pressures. The contours or inscribed selectivities of nuclear risks had spatial elements (for example those in closest proximity to the nuclear site were evacuated) and socio-cultural/economic elements (for example farmers and fishermen lost livelihoods). Stratified across Japanese society heterogeneous groups of citizen actors engaged in strategies in relation to a process of reflexive social learning (see for example Muro and Jeffrey 2008), forming new collectives to galvanise opposition to nuclear power and challenge the spatio-temporal identities of the agents within the atomic village. These actors formulated strategies to overcome the strategically selective context that had thus far inhibited public anti-nuclear discourse, leading to shifts within the previously stable spatio-temporal fix. It is in this way that the material intervention of the Fukushima disaster provided opportunities for new forms of socio-cultural organisation, opening up political debate about nuclear power not just in Japan, but in all nuclear power producing countries, alongside a space for new forms of sociotechnical systems to be deliberated upon, as renewable energy expansion was seriously considered to fill the nuclear gap (Barrett 2012). As Butler et al. (2011) suggest, though the disaster may not have provoked entirely new cultural discourses around nuclear power due to the path dependency of stable structural configurations of nuclear power renewal; it has acted as a catalyst for reflection and the re-emergence of alternative frames of nuclear policy (including anti-nuclear and pro-renewables frames), and new agential strategies. This strategic learning process has generated the political capacity for opposition groups to engage in strategic context analysis and then pursue variably adapted strategies in the face of previous structural selectivities. They also engage in strategic actions to circumvent and modify prior constraints. In this case strategic learning and action is evident through growing awareness of nuclear risks through information sharing campaigns (Ikegami 2012), successful campaigns against 
new nuclear build across different political scales within local government, the courts and through non-violent direct action campaigns, the resignation of Prime Minister Naoto Kan, a persistent fear and long-lasting cultural memory of danger surrounding nuclear institutions and technologies, learning across different national contexts of domestic nuclear production (including both transformational policy change in Germany and Italy), calls for global regulatory instruments for the industry, and the breaking the sovereignty of nuclear systems (for evidence of and discusison of these facets, see Nishioka 2011; Brumfiel and Fuyono 2012; Hagmann 2012; Wittneben 2012).

\section{Materiality and the strategic relational approach}

The SRA posits strategy as the mediator of the structure-agency dialectic, and this logically entails a related dialectic of the material and ideational (Marsh 2002). Herein lies the flaw. The SRA privileges the agency of human actors and the realm of ideas. The evidence lies in the two core facets of the SRA: the capturing of political narratives (namely crisis narratives), and actors' learning capabilities leading to strategy formation in response to a discursive interpretation of the contours of strategic selectivity that prioritise certain agents' interests over others. Hay acknowledges that the material and ideational are dialectically related, and argues that the ideational realm has 'real' effects on the material world. However, as Kuipers (2006) argues, there are constraints on policy change and narratives resulting from the uneven distribution of resources and that this is weakly conceptualised in the SRA model. Jessop and Hay's emphasis on strategy largely brackets out the effects of natural resources, material artefacts and physical processes. I would argue also although the discursive ideational realm has 'real' effects on the material realm in Hay's model, and critiques such as Marsh's (2010) where material resources are posited to exist alongside discursive resources in actors' capacity to enforce change and physical processes do appear, these material aspects are construed as value neutral - in the sense that it is human agents' free will and autonomy that wields these resources and thus it is only humans that are constrained within structured settings.

In the field of risk studies, exploring the relationship between the materiality of hazards and the social construction of risks is nothing new (Wynne 1985; Douglas 1986; Bord and O'Conner 1990; Warner 1992). The Fukushima example clearly shows that a human agent-biased explanation is untenable without adequate conceptualisation of the materiality of risk. For example, the physical properties of radionuclide migration on air and sea influence the spatial characteristics of strategic selectivities - notably the $20 \mathrm{~km}$ exclusion zone around the Fukushima plant caused the evacuation of approximately 170,000 people through enforced and voluntary migration, pushing refugees into temporary housing without employment, food contamination and ongoing concerns about cancer risks and other physical health effects. This has caused significant environmental injustice, disproportionately affecting the burakumin - the stigmatised and economically coerced working poor (in this case radiation workers, see Shrader-Frechette 2012). Moreover, bans and restrictions from contaminated produce in the affected areas (both land and sea), alongside the shutdown of existing nuclear energy capacity and future clean-up costs over an estimated 40 year period bring the total estimated cost to the Japanese economy in the region of $\$ 235$ billion, making it one of the world's greatest disasters (von Hippel 2011; World Energy Council 2012). If we are to have a true material-ideational dialectic in understanding political and social change then an alternative resource and technology-based model of strategy is needed, whereby human and non-human resource elements are mobilised in concert with one another in order for strategic action to succeed. 
The material-ideational dialectic can be interpreted in Foucauldian terms (1978) as a type of dispositif. The terminology of dispositifs has been variously translated in the sociological literature as either as 'apparatus', 'tools and devices' (Rabinow 2003) or purposefully designed systems (Caborn 2007) - referring to the institutionalisation of praxis through the heterogeneous ensemble of discursive practices, actions and objects, and the system of relations that are established between these elements (Pløger 2008; Jäger 2001). In essence dispositif encompasses the materiality implicit within social discourse, directly linking it back to specific, social practices - whereby speech acts, thoughts and shared systems of knowledge are dialectically related to non-discursive behaviours and actions (praxis). It is through the manifestations of knowledge by means of acts or behaviours and by extension objects and other physical artefacts (Jäger 2001) that dispositives emerge. By 'scaling up' from individuals and individual units of language and action one can understand broader relationships between discourse, institutional practices and societal change (Bührmann and Schneider 2007), in essence a material-ideational dialectic.

The SRA provides an analytical device through which to understand the dialectical relationships of discourse, institutional practice and social change; and yet the thin conceptualisation of materiality remains a fundamental ontological weakness that needs to be addressed in analysing the material-ideational dialectic. Thus, by drawing upon the ActorNetwork Theory (ANT) from the sociology of science and technology, a suitable conceptual bridge can be found to links the SRA and material risk politics as it provides a nuanced conceptualisation of technology and material resource strategy. The aim is to integrate this with the ontology of the SRA to overcome the latter's relatively weak conception of materiality in influencing social and political change. ANT is construed as a materialsemiotic explanatory framework for revealing the assemblages of social and technical elements - and hence there is a focus upon sociotechnical systems as the point of analysis. ANT proffers a material-ideational ontological relationship which is flat structured, whereby symmetry is proposed between heterogeneous elements. Technological artefacts, devices, resources, texts and human agents have equal footing, thus rejecting the dichotomy of technological determinism and social determinism as descriptors of change (Callon 1987; Latour 1993, 2004; Law and Hassard 1999). The ANT tradition emphasises the how human actors forge alliances and negotiations with non-human as well as human actors, so power is accumulated and maintained through alliances with technologies, materials and other nonhuman allies, as well as those with other people (Lee and Brown 1994; Latour 2005).

Jessop's work on cultural political economy notes the value of ANT. He argues that the Marxist interpretation of political economy is situated within a broader cultural turn within the social sciences (hence cultural political economy); one that challenges the traditional political economic reification of technical and economic objects such as land tools, and machines. By contrast, cultural political economy expresses how such objects are culturally and historically embedded, and thus socially constructed and embodied. Jessop links this Marxist critique of PE to ANT through recognising a shared relational ontology (the mutual co-constitution and co-evolution of material and social), the rejection of objective and functionalist essentialism, and the denial of fixed macro and micro scale (Jessop 2005b). These mutual ontological underpinning provide a stepping stone between ANT and the dialectical approaches to structure and agency, and stability and change present in the SRA. What ANT adds is an emphasis upon the stability or instability of relationships between human and non-human elements as the thing that defines technological progress and social change. Change is construed as a struggle of holding in place, relations need to be repeatedly performed or the network will dissolve. Analytical therefore attention moves from the intentions or purposes of actors (as predominates in the SRA) towards the ways in which they attempt to increase the remit of their actions by holding other (actors and artefacts) in place, 
and escaping this holding effect that others impinge upon them (Latour 1993). Within this model, the strategically selective context is formed of alliances between these symmetrical heterogeneous elements. Thus we can talk about a relationship between 'actants' (encompassing these heterogenous elements) and 'actantiality' rather than simply agency, implying more than just strategic action, rather the conditions under which human and nonhuman elements of a network are provided with their actions, subjectivity and intentionality. Thus different actants may be "enrolled" as "allied" to reinforce network relationships and the stability and form of these actants should be seen as a function of the interaction of heterogeneous elements as these are shaped and assimilated into a network (Law and Hassard 1999). Thus strategy as action in context and strategic learning as a force of social change is replaced with a focus on heterogeneous assemblages of allied actants as the mediator of structure and agency (see for example Lee and Brown 1994).

\section{Building a hybrid ontological model}

Critical in trying to build a hybridised ANT-SRA model is the notion that alliance between heterogeneous elements is fundamental to formulating a concept of agency. Figure 1 is produced with direct reference to the structure-strategy-agency model that Hay (2002b) presents in his book Political Analysis. What precedes the concept of the strategic actor in this hybridized model, is the enrolment of different actants (in the diagram 'material artefact' is used as a category, though other heterogenous elements such as non-human animals, data, policies etc. can similarly be enrolled). I argue that it is this process of enrolment that produces the dialectic of material and ideational factors that in turn produces the strategically selective context that constitutes the ontological category of 'structure'. Thus, rather than a strategic actor-social structure duality, we are presented instead with an alliance-selective context duality that forms the first part of the dialectical 'loop'.

In the model presented in Figure 1, human and non-human elements are separated, though the principle of generalized symmetry is retained, and the entelechy (the mixing of non-human and human elements) based upon the alliances between them. In line with ANT ontology it is a combination of the scripting capabilities of these enrolled actants - the heterogeneous human and non-human elements become mutually associated and juxtaposed and thus inscribe scripts into the design objects and conforming social practices, and these mutually shape one another, and the strategizing of human actors that produces the second phase of the dialectical 'loop'. The strategically inscribed selectivities are thus interpreted (by human actors), and scripted by non-human actors (such as technological artefacts and processes) to produce actantiality - the conditions under which actions are performed. Thus strategy (a human-actor oriented process) is augmented by this material-ideational dialectic. Strategic human actors learn of their associated constraints (including material constraints) which stimulates a change in strategic ideas (i.e. they formulate new strategies on the basis of a process of social learning). Material artefacts embedded in sociotechnical systems are simultaneously transformed. In keeping with the punctuated equilibrium model of stability and change, the scale of these interactions can then be differentiated. In ANT terms this is akin to the difference between intermediaries and mediators (Latour 2005). Intermediaries are entities which enact little or no change in the sense that they produce little over all transformation (and hence stability), whereas mediators are entities which multiply difference producing instability (in ANT terms their 'outputs' are not equal to their 'inputs') (ibid.). In SRA terms this means that in the realm of ideas those actantialities that reproduce spatiotemporal fixes (i.e. stable configurations) are contrasted with those that produce punctuation (revolutions). 
As a dialectical process this is an Alliance-Context-Actantiality (ACA) model which can be mapped diachronically. Alliances between heterogeneous actants produce contextspecific structured settings which privilege certain actants over others. This in turn inscribes the conditions of actantiality - the capacity of certain actants to either alter the associated constraints to their capacity to 'act' and thus transform social and material worlds (or not, as the case may be). These processes can be separated analytically by comparing change over time, as shown in points A, B, C in Figure 1. Actants reflect back on past change in the formulation of new strategies (if they are human) and new scripts are developed (in the case or artefacts). Whether each loop of this dialectic reproduces evolution or punctuation is a question of the scale of the effect: i.e. whether or not actants become intermediaries that reproduce stability or mediators that effect change. In either case, new actants and networks emerge that are either more or less transformed by the process. In keeping with both the SRA and ANT traditions, the model remains deeply performative - it is process-oriented whereby these heterogenous assemblages remain in constant flux, recreating and transforming structure and agency through a dialectic of material and ideational assemblages reconfiguring themselves over time.

\section{A brief post-Fukushima nuclear policy example}

In this final section, I examine a very brief sketch of how this model could be applied to examining the influence of the Fukushima disaster upon Japanese nuclear energy policy. In 2006, during Prime Minister Abe's first stint in office, he oversaw Japan's Nuclear Energy National Plan (Nuclear Energy Policy Planning Division 2006) which explicitly couched policy in energy security terms, promoting a strategy of adopting both nuclear and renewable energy to meet the material needs of Japanese society; simultaneously plugging a growing energy gap, and decarbonising electricity systems in line with post-Kyoto climate change mitigation targets. Here the dialectic of material artefacts (the configuration of nuclear power technologies, regional electricity transmission systems, in the context of fossil fuel and renewable resource constrained energy production) is allied with political actors within the Atomic Village, climate scientists and energy security experts to form a strategically selective context that favours energy policy captured within a narrative of long-term energy security in a fossil fuel resource scarce nation. Together these alliances generate a strategically selective context in which the material-ideational dialectic of energy security emerges - and the Atomic Village formulated the energy security strategy-within-context that reinforced a pronuclear policy environment. What happened then, however, is the external and material intervention of the Fukushima disaster, which reconfigures the actantiality of these heterogeneous elements. The material artefacts in the socio-technical system of nuclear power production underwent radical material-ideational transformation: they are re-scripted from energy security necessities to socially undesirable risk burdens, shifting status from intermediaries to mediators. This in turn influences processes of social learning about nuclear risk amongst human actors within civil society (evidenced by mass protest, legal challenges and loss of pro-nuclear authority within mainstream democratic politics), and socio-technical system instability. In ANT terms this amounts to instability within the actor-network leading to punctuation (in the SRA framework), evidenced by the shutdown of all domestic nuclear power production in Japan since 2011.

However, within the ACA model this period of instability in turn creates a new strategically selective context in which new alliances of actants emerge. What we see with Japanese energy policy in 2014 under the Basic Energy Plan (the first post-Fukushima nuclear energy policy plan) is that the material constraints of energy production have become 
acute following the shutdown of domestic nuclear production. Japan now has the lowest energy self-sufficiency rate of any of the G8 nations (currently 4\% with nuclear power offline), compounded by a paucity of domestic fossil fuel resources, and a lack interconnected electricity and gas transmission systems to form a northeast Asian regional power grid (similar to that seen in Western Europe) (Toyoda 2012). The shutdown of nuclear has thus created further actor-network instability and hence a new strategically selective context. Strategic actors within the Atomic Village have formulated a new ideational narrative of energy security, and we are beginning to see a reversal of the zero-nuclear trend seen since April 2011. The basic plan again opts for a mix of nuclear, renewables and fossil fuels. Nuclear energy has become once again an intermediary: a stable 'normal' system that meets the goals of a slowly evolving low-carbon energy system transition. This new evolutionary period of nuclear renewal emerged in the context not only of low energy selfsufficiency, but also the policy costs of the socio-technical system - including regulatory measures and macroeconomic implications for Japanese export industries associated with the current "zero nuclear" scenario (Kilisek 2014). What we see, therefore, is that the punctuated period of sociotechnical system disruption has now ended. Dominant political actors within the Atomic Village have reasserted the pro-nuclear narrative, formed through alliances of human relationships amongst a powerful political elite, and alliances with non-human technical artefacts, the science of climate change, and the economics of energy production. The actantiality of nuclear power in Japan is thus forged through the material-ideational dialectic of energy security which is beginning to overcome the crisis narrative of socially unacceptable risk burdens borne by domestic nuclear power.

\section{Conclusion}

The proposed hybrid Alliance-Context-Actantiality (ACA) model is an attempt to draw materiality into a meta-theoretical model of stability and change, structure and agency in a manner that blends both the Strategic-Relational Approach and Actor Network Theory traditions. This has implications for how we understand rapid change in the wake of physical, technological interventions into a pattern of otherwise stable policy evolution. In the Strategic-Relational Approach (SRA) one can understand how policy actors under conditions of crisis engage in narrative conflict with opponents. They either reproduce the goals of those actors strategically privileged by the contours of the structured setting and ensure stability (evolution), or else fail to capture the crisis narrative and revolutionise the structured setting, destabilising the 'spatio-temporal fix' of the prevailing policy. When it comes to the analysis of risk and the understanding of socio-technical systems it is materiality that is missing from the SRA. In the hybrid ACA model it is the alliance of material artefacts, physical processes and human actors that produces the contoured strategically selective context. The structurally privileged position of certain human actors is disrupted and destabilised when alliances between them and other (human and non-human) actants breaks down. It is the relative stability of the alliances between these heterogeneous elements that allows actants to break free of their associated constraints. Therefore, though the ontologies of the SRA and ANT have differing conceptions of what constitutes 'the social' and 'the material' this hybrid model provides a programmatic proposal from which to draw together political science and ANT descriptions of social and technological stability and change within the policy arena; and the Fukushima disaster provides a suitable lens through which to view material interventions in the realm of (what is otherwise conceived of as) ideational politics. 
Augmenting the SRA with its focus on structure, strategy and agency into an AllianceContext-Actantiality model thus provides a potentially fruitful means through which to interrogate policy stability and change whilst maintaining a nuanced conception of the material. 
Figure 1. Alliance, Context and Actantiality - a model of socio-technical change
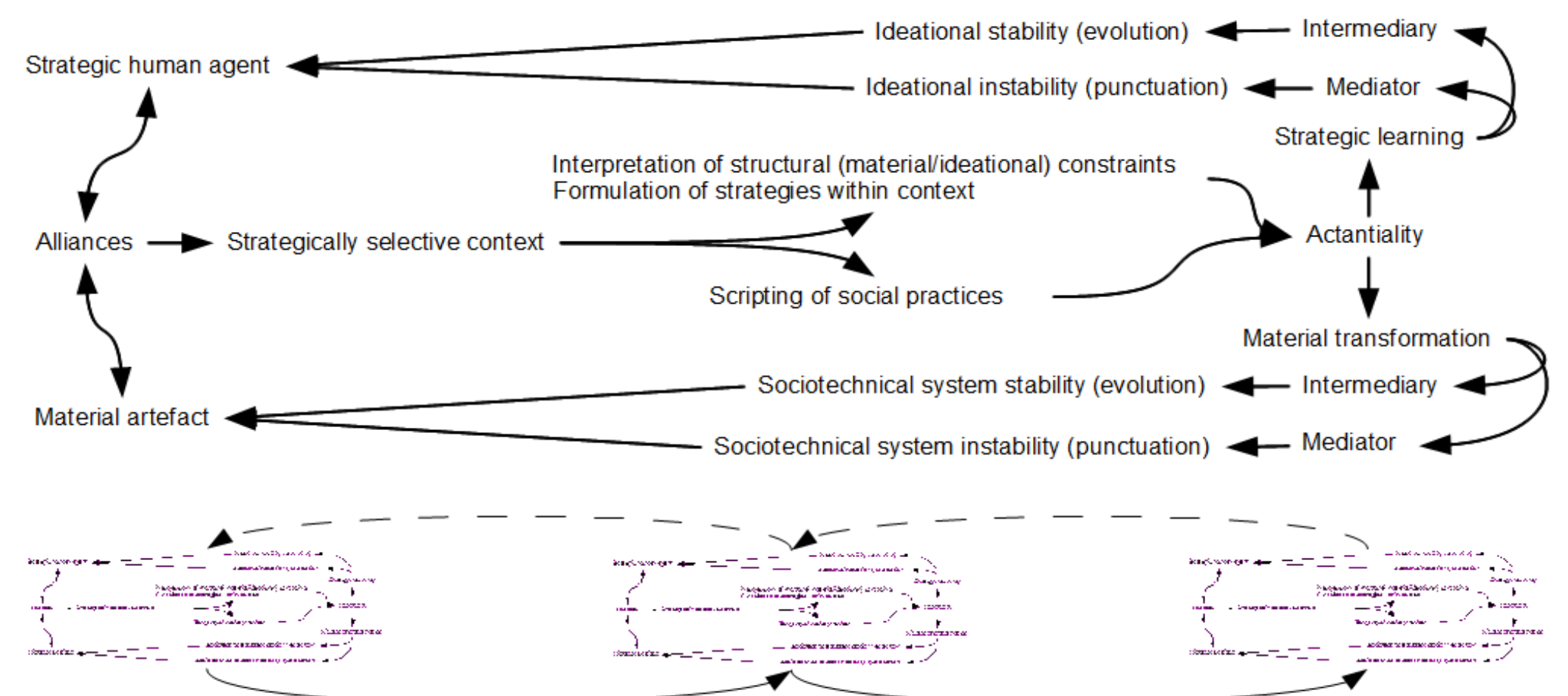

A

B

C 


\section{References}

Adler, E. 1997. Seizing the Middle Ground: Constructivism in World Politics. European Journal of International Relations 3 (3):319-363.

Aldrich, D.P. 2012. Post-Crisis Japanese Nuclear Policy: From Top-down Directives to Bottom-up Activism. Analysis from the East-West Center 103:1-12.

Archer, M. 2003. Structure, Agency and the Internal Conversation. Cambridge: Cambridge University Press.

Barrett, B. 2012. After the Nuclear Disaster, Japan Considers a Green Future. Solutions 3 (1):99-103.

Beck, U. 1987. The anthropological shock: Chernobyl and the contours of the risk society. Berkeley Journal of Sociology 32 (153-165).

Beck, U. 1992. Risk Society: Towards a New Modernity. London: Sage.

Bickerstaff, K., I. Lorenzoni, N.F. Pidgeon, W. Poortinga, and P. Simmons. 2008. Reframing Nuclear Power in the UK Energy Debate: Nuclear Power, Climate Change Mitigation and Radioactive Waste. Public Understanding of Science 17:145-169.

Blowers, A. 2011. Why Fukushima is a moral issue? The need for an ethic for the future in the debate about the future of nuclear energy. Journal of Integrative Environmental Sciences 8 (2):73-80.

Bord, R.J., and R.E. O'Conner. 1990. Risk communication, knowledge, and attitudes: explaining reactions to a technology perceived as risky. Risk Analysis 10 (4):499-506.

Brooks, Thom. 2012. After Fukushima Daiichi: New Global Institutions for Improved Nuclear Power Policy. Ethics, Policy \& Environment 15 (1):63-69. doi:10.1080/21550085.2012.672689.

Brumfiel, G., and I. Fuyono. 2012. Fukushima's legacy of fear. Nature 483:138-140.

Bührmann, A.D., and W. Schneider. 2007. More Than Just a Discursive Practice? Conceptual Principles and Methodological Aspects of Dispositif Analysis. Forum: Qualitative Social Reseach Sozialforschung.

Butler, Catherine, Karen A. Parkhill, and Nicholas F. Pidgeon. 2011. Nuclear Power After Japan: The Social Dimensions. Environment: Science and Policy for Sustainable Development 53 (6):3-14. doi:10.1080/00139157.2011.623051.

Caborn, J. 2007. On the Methodology of Dispositive Analysis. Critical Approaches to Discourse Analysis Across Disciplines 1 (1):115-123.

Callon, M. 1987. Society in the Making: The Study of Technology as a Tool for Sociological Analysis. In The Social Construction of Technological Systems: New Directions in the Sociology and History of Technology, ed. W.E. Bijker, T.P.Hughes, T.P., Pinch, T.J., 83-103. Cambridge, MA: MIT Press.

Carlsnaes, W. 1992. The Agency-Structure Problem in Foreign Policy Analysis. International Studies Quarterly 36:245-270.

Craib, I. 1992. Anthony Giddens. London: Routledge.

Douglas, M. 1986. Risk Acceptability According to the Social Sciences. London: Sage.

Foucault, M. . 1978. Dispositive der Macht. Über Sexualität, Wissen und Wahrheit. Berlin: Merve.

Foxon, Timothy J., Geoffrey P. Hammond, and Peter J. G. Pearson. 2010. Developing transition pathways for a low carbon electricity system in the UK. Technological Forecasting and Social Change 77 (8):1203-1213. doi:10.1016/j.techfore.2010.04.002. 
Fuller, S. 1998. From Context to Context: A Social Epistemology of the Structure-Agency Craze. In What is Social Theory? The Philosophical Debates, ed. A. Sica. Oxford: Blackwell.

Funabashi, Harutoshi. 2012. Why the Fukushima Nuclear Disaster is a Man-made Calamity. International Journal of Japanese Sociology 21 (1):65-75. doi:10.1111/j.14756781.2012.01161.x.

Geels, F.W. 2002. Technological transitions as evolutionary reconfiguration processes: a multi-level perspective and a case-study. Research Policy 31 (8-9):1257-1274.

Geels, F.W. 2004. From sectoral systems of innovation to socio-technical systems: Insights about dynamics and change from sociology and institutional theory. Research Policy $33(6 / 7): 897-920$.

Giddens, A. 1979. Central problems in social theory: Action, structure and contradiction in social analysis. London: MacMillan.

Giddens, A. 1984. The Constitution of Society: Outline of the Theory of Structuration. Cambridge: Polity Press.

Gregson, N. 2005. Agency: Structure. In Spaces of Geographical Thought, eds. P. Cloke, and R. Johnston. London: Sage.

Hagmann, Jonas. 2012. Fukushima: probing the analytical and epistemological limits of risk analysis. Journal of Risk Research:1-15. doi:10.1080/13669877.2012.657223.

Hall, P. 1993. Policy paradigms, social learning and the state. Comparative Politics 25 (3):175-196.

Hasegawa, K. 2010. Collaborative Environmentalism in Japan. In Civic Engagement in Contemporary Japan, eds. H. Vinken, Y. Nishimura, B.L.J. White, and M. Deguchi. Berlin: Springer.

Hasegawa, K. 2012a. Facing Nuclear Risks: Lessons from the Fukushima Nuclear Disaster. International Journal of Japanese Sociology 21 (1):84-91. doi:10.1111/j.14756781.2012.01164.x.

Hasegawa, K. 2012b. Toward a Post-Nuclear Society: Examining the 3/11 Disaster and Nuclear Risks. Paper presented at the Symposium, Towards Long-term Sustainability: In Response to the 3/11 Earthquake and the Fukushima Nuclear Disaster, The Center for Japanese Studies, University of California, Berkeley, 20-21 April, 2012

Hay, C. 1995. Structure and Agency. In Theory and Methods in Political Science, eds. D. Marsh, and G. Stoker. London: MacMillan.

Hay, C. 1996. Re-Stating Social and Political Change. Buckingham: Open University Press.

Hay, C. 2002a. Globalisation as a Problem of Political Analysis: Restoring Agents to a 'Process without a Subject' and Politics to a Logic of Economic Compulsion. Cambridge Review of International Affairs 15 (3):379-392.

Hay, C. 2002b. Political Analysis. A Critical Introduction. Basingstoke: Palgrave.

Hay, C., and D. Wincott. 1998. Structure, Agency and Historical Institutionalism. Political Studies 46 (5):951-957.

Hoffmann-Riem, Holger, and Brian Wynne. 2002. In risk assessment, one has to admit ignorance. Nature 416 (6877):123-123.

Ikegami, Y. 2012. People's movement under the radioactive rain. Inter-Asia Cultural Studies. doi:DOI:10.1080/14649373.2012.639338.

Jäger, S. 2001. Discourse and knowledge. Theoretical and methodological aspects of a critical discourse and dispositive analysis. In Methods of Critical Discourse Analysis, eds. R. Wodak, and M. Meyer, 32-62. London: Sage.

Jessop, B. 2001. Institutional re (turns) and the strategic-relational approach. Environment and Planning A 33 (7):1213-1235. 
Jessop, B. 2005a. Critical Realism and the Strategic-Relational Approach. New Formations $56(1): 40-53$.

Jessop, B. 2005b. Cultural political economy, the knowledge-based economy and the state. In The Technological Economy, eds. A. Barry, and D. Slater. London: Routledge.

Jessop, B. 2006. Spatial fixes, temporal fixes and spatio-temporal fixes. In David Harvey: A Critical Reader, eds. N. Castree, and D. Gregory, 142 -166. Oxford: Blackwell.

Jessop, B. 2007. State Power: A Strategic-Relational Approach. Cambridge: Polity.

Joscow, P.L., and J.E. Parsons. 2012. The Future of Nuclear Power After Fukushima. Cambridge, MA: MIT Center for Energy and Environmental Policy Research.

Kilisek, R. 2014. Energy 'Policy Costs' Impact Japan's International Competitiveness. The Energy Collective.

Kuhn, T.S. 1962. The Structure of Scientific Revolutions. Chicago, IL: University of Chicago Press.

Kuipers, S. 2006. The crisis imperative: crisis rhetoric and welfare state reform in Belgium and the Netherlands in the early 1990s. Amsterdam: Amsterdam University Press.

Latour, B. 1993. We have never been modern. Hemel Hempstead: Harvester Wheatsheaf.

Latour, B. 2004. Politics of Nature: How to Bring the Sciences into Democracy. Cambridge MA: Harvard University Press.

Latour, B. 2005. Reassembling the social: an introduction to actor-network-theory. Oxford: Oxford University Press.

Law, J., and J. Hassard. 1999. Actor Network Theory and After. Oxford: Blackwell.

Lee, N. , and S. Brown. 1994. Otherness and the Actor-network: The Undiscovered Continent. American Behavioral Scientist 37 (6):772-790.

Marsh, D., Furlong, P. 2002. A Skin, not a Sweater: Ontology and Epistemology in Political Sciences. In Theory and Methods in Political Science, ed. D. Marsh, Stoker, G. Hampshire: Palgrave.

Marsh, David. 2010. Stability and change: the last dualism? Critical Policy Studies 4 (1):86101. doi:10.1080/19460171003715036.

Masako, T. 2012. Fukushima's Impact on Japan's Nuclear Fuel Cycle Policy: James Martin Center for Nonproliferation Studies (CNS).

McAnnulla, S. 2002. Structure and Agency. In Theory and Methods in Political Science, ed. D. Marsh, Stoker, G. Basingstoke: Palgrave.

McAnulla, S. 2005. Making Hay with Actualism? The Need for a Realist Concept of Structure. Politics 25 (1):31-38.

McGuirk, P.M. 2004. State, strategy, and scale in the competitive city: a neo-Gramscian analysis of the governance of 'global Sydney'. Environment and Planning A 36:10191043.

Meltzer, J. . 2011. After Fukushima: What's Next for Japan's Energy and Climate Change Policy? Washington D.C.: Brookings Institution.

Muro, M., and P. Jeffrey. 2008. A critical review of the theory and application of social learning in participatory natural resource management processes. Journal of Environmental Planning and Management 51 (3):325-344. doi:10.1080/09640560801977190.

Nishioka, N. 2011. Towards a peaceful society without nuclear energy: understanding the power structures behind the 3:11 Fukushima nuclear disaster. The Asia Pacific Journal 9 (52).

Nuclear Energy Policy Planning Division. 2006. The Challenges and Directions for Nuclear Energy Policy in Japan: Japan's Nuclear Energy National Plan. Tokyo: Ministry of Economy, Trade and Industry (METI). 
O’Brien, M., Penna, S., Hay, C. 1999. Theorising Modernity: Reflexivity, Environment and Identity in Giddens Social Theory. London: Longman.

Pløger, John. 2008. Foucault's Dispositif and the City. Planning Theory 7 (1):51-70. doi:10.1177/1473095207085665.

Rabinow, P. 2003. Anthropos Today. Reflections on Modern Equipment. Princeton, NJ: Princeton University Press.

Reed, M.I. 1997. In praise of duality and dualism: rethinking agency and structure in organizational analysis. Organization Studies 18 (1):21-42.

Rieu, Alain-Marc. 2013. Thinking after Fukushima. Epistemic shift in social sciences. Asia Europe Journal 11 (1):65-78. doi:10.1007/s10308-013-0344-8.

Sewell Jr, W.H. 1992. A Theory of Structure: Duality, Agency, and Transformation. The American Journal of Sociology 98 (1):1-29.

Shrader-Frechette, K. 2012. Nuclear Catastrophe, Disaster-Related Environmental Injustice, and Fukushima, Japan: Prima-Facie Evidence for a Japanese "Katrina". Environmental Justice 5 (3):133-139.

Shrader-Frechette, Kristin. 2011. Fukushima, Flawed Epistemology, and Black-Swan Events. Ethics, Policy \& Environment 14 (3):267-272. doi:10.1080/21550085.2011.605851.

Swyngedouw, E. 2007. Impossible sustainability and the post-political condition. In The Sustainable Development Paradox: urban political economy in the US and Europe, eds. R. Krueger, and D. Gibbs, 13- 40. New York: Guildfor Press.

Taleb, N. 2007. The Black Swan: The Impact of the Highly Improbable London: Random House.

2012. Fukushima's Impact on Japan's Nuclear Fuel Cycle Policy. 09/03/2012.

Toyoda, M. 2012. Energy security and challenges for Japan. Tokyo: The Institute of Energy Economics.

von Hippel, F. N. 2011. The radiological and psychological consequences of the Fukushima Daiichi accident. Bulletin of the Atomic Scientists 67 (5):27-36. doi:10.1177/0096340211421588.

Warner, F. 1992. Risk: Analysis, Perception and Managment. London: The Royal Society.

Willmott, R. 1999. Structure, Agency and the Sociology of Education: rescuing analytical dualism. British Journal of Sociology of Education 20 (1):5-21.

Wittneben, Bettina B. F. 2012. The impact of the Fukushima nuclear accident on European energy policy. Environmental Science \&amp; Policy 15 (1):1-3. doi:10.1016/j.envsci.2011.09.002.

World Energy Council. 2012. World Energy Perspective: Nuclear Energy One Year After Fukushima. London: World Energy Council.

World Nuclear Association. 2012. Policy Responses to the Fukushima Accident. http://www.world-nuclear.org/briefings/policy_responses_fukushima_accident.html. Accessed 13/01/2012 2012.

Wynne, B. 1985. From Public Perception of Risk to Technology as Cultural Process. In Environmental Impact Assessment Technology and Risk analysis, ed. V. Covello et al. Berlin: Springer. 